\title{
Levels of Organochlorine Pesticides and Heavy Metals in Surface Waters of Konya Closed Basin, Turkey
}

\author{
Mehmet Emin Aydin, Senar Ozcan, Fatma Beduk, and Ali Tor \\ Department of Environmental Engineering, Necmettin Erbakan University, 42060 Konya, Turkey \\ Correspondence should be addressed to Fatma Beduk; fabeduk@konya.edu.tr
}

Received 28 December 2012; Accepted 17 January 2013

Academic Editors: S. Bhattacharya, N. Fontanals, and J.-F. Liu

Copyright ( 2013 Mehmet Emin Aydin et al. This is an open access article distributed under the Creative Commons Attribution License, which permits unrestricted use, distribution, and reproduction in any medium, provided the original work is properly cited.

The concentrations of organochlorine pesticides (OCPs), including $\alpha-, \beta-, \gamma$-, and $\delta$-hexachlorocyclohexane (HCH), heptachlor, heptachlor epoxide, dieldrin, aldrin, endrin, endrin aldehyde, endrin ketone, endosulfan I, endosulfan II, endosulfan sulfate, p, p' DDE, p, p'-DDD, p, p'-DDT, methoxychlor, chlordane I, chlordane II, and heavy metals, such as As, $\mathrm{Cr}, \mathrm{Cu}, \mathrm{Fe}, \mathrm{Mn}$, and Ni in surface water samples from the Konya closed basin were determined to evaluate the level of contamination. Among all $\mathrm{HCH}$ isomers, $\beta$ $\mathrm{HCH}$ is the main isomer with a concentration range of $0.015-0.065 \mu \mathrm{g} / \mathrm{L}$. DDE, DDD, and DDT were almost determined in all samples, in which DDE isomer had the highest concentration ranged from not detected to $0.037 \mu \mathrm{g} / \mathrm{L}$. In all studied OCPs, aldrin showed the highest concentration at $0.220 \mu \mathrm{g} / \mathrm{L}$. The concentrations of heavy metals in water samples were observed with order: $\mathrm{Mn}<\mathrm{Cu}<\mathrm{Ni}<\mathrm{As}<\mathrm{Cr}<\mathrm{Fe}$. In some samples, As, Fe, and $\mathrm{Cr}$ concentrations exceeded the drinking water quality recommended by EU, US EPA, WHO, and Turkish Regulation, while $\mathrm{Cu}, \mathrm{Ni}$, and $\mathrm{Mn}$ concentrations are below the guideline values. The levels of both OCPs and heavy metals were also compared with other previously published data.

\section{Introduction}

Heavy metals occur naturally in soils and rocks entering the biogeochemical cycle. Anthropogenic releases, including industrial and domestic effluents, urban storm, water runoff, landfill leachate, atmospheric sources, coal-burning power plants, nonferrous metal smelteries, iron and steel plants, and dumping of sewage sludge can give rise to higher concentrations of the metals relative to the normal background values [1-3]. Heavy metals that enter aquatic system are ultimately deposited in suspended particulate matter and sediments that can be a long-term source of contamination [4]. Excess of some essential metals can damage human health, and nonessential metals can be toxic at even very low concentrations $[5,6]$.

Organochlorine pesticides (OCPs) have been used for decades in control of agricultural pests. Although most of OCPs were banned in many developed countries, some developing countries are still applying them for agricultural and public health purposes due to their low cost [7]. They accumulate in the environment owing to their persistence and lipophilic properties $[8,9]$. High levels of OCPs are still being detected in various environmental media, especially in seafood [10].

Konya watershed is a closed basin and has 4.52 billion $\mathrm{m}^{3}$ water capacity. Konya closed basin has semiarid climate and limited water sources. Water shortage is faced because of increasing water demand due to the increasing population and expansion of the agricultural and industrial production. Uncontrolled drilled bore-holes for irrigation purposes and water abstraction intensified water shortage. Determination of the quality of existing limited water sources in Konya closed basin and identifying pollutant sources is of great importance. Most of the scientific efforts on the basin were carried out for extensive exploitation of groundwater that causes sinkhole development. On the other hand, a monitoring of the organic and inorganic contamination of water sources of the basin is lacking. Detection and quantification of a low contamination of OCPs and heavy metals in waters have become vital due to the toxicity of these contaminants to living organisms and humans [11]. Adverse effects of these contaminants on human health make it necessary to 


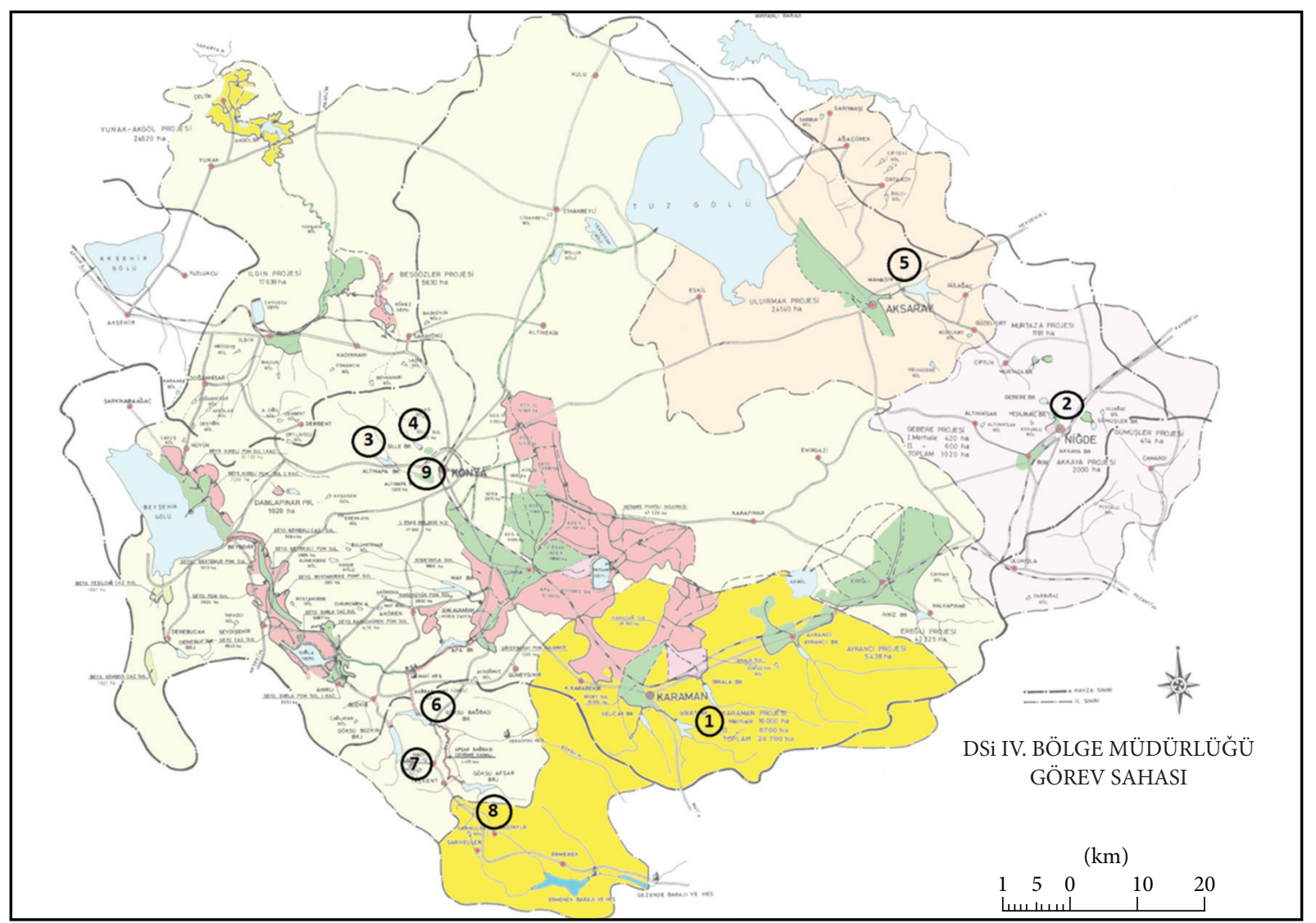

Figure 1: Map of the study area and sampling points (1) Ibrala stream; (2) Kirkgozler spring; (3) Basarakavak stream; (4) Meram stream; (5) Mamasin dam; (6) Bagbasi dam derivation tunnel inlet; (7) Bozkir stream; (8) Afsarllicapinar stream; (9) Altinapa dam).

determine the concentration of these elements in water sources. Therefore, the objectives of this study are to investigate the levels of heavy metal (As, $\mathrm{Cr}, \mathrm{Cu}, \mathrm{Fe}, \mathrm{Mn}$, and $\mathrm{Ni}$ ) and OCPs, including $\alpha$-, $\beta$-, $\gamma$-, and $\delta$-hexachlorocyclohexane $(\mathrm{HCH})$, heptachlor, heptachlor epoxide, dieldrin, aldrin, endrin, endrin aldehyde, endrin ketone, endosulfan I, endosulfan II, endosulfan sulfate, $p, p^{\prime}$-DDE, p, p'-DDD, p, p' DDT, methoxychlor, chlordane I, and chlordane II in selected surface waters that can be drinking water sources in Konya closed basin, in order to provide a sufficient data for developing realistic risk reduction measures.

\section{Experimental}

2.1. Reagents and Solvents. All chemicals used were of analytical grade. The mixed standard of OCPs, including $\alpha$-, $\beta-, \gamma-$, and $\delta$-hexachlorocyclohexane $(\mathrm{HCH})$, heptachlor, heptachlor epoxide, dieldrin, aldrin, endrin, endrin aldehyde, endrin ketone, endosulfan I, endosulfan II, endosulfan sulfate $\mathrm{p}, \mathrm{p}^{1}$-DDE, $\mathrm{p}, \mathrm{p}^{1}$-DDD, $\mathrm{p}, \mathrm{p}^{1}$-DDT, methoxychlor, chlordane I, and chlordane II was obtained from Accustandard Co. (NewHaven, CT, USA). Standard stock solutions of $10 \mathrm{mg} / \mathrm{L}$ were prepared in methanol for each organic group.

Acetone, $n$-hexane, and dichloromethane were of residue grade (Merck, Germany). Anhydrous sodium sulphate was obtained from Merck, Germany. Metal standard stock solutions including $\mathrm{As}, \mathrm{Cu}, \mathrm{Cr}, \mathrm{Fe}, \mathrm{Mn}$, and $\mathrm{Ni}$ were also from Merck. All solutions were stored in the dark at $4^{\circ} \mathrm{C}$.

2.2. Study Site. Konya closed basin is the largest closed basin of Turkey. There are many streams, lakes, and wetland areas. The water sources of Konya closed basin are only rainfall. After completing the circulation from underground and from surface in the basin, the water reaches to Salt Lake. Due to its large grassy steppes, biological diversity, and wetlands, Salt Lake is one of the 200 most important ecological regions in the world [12]. Konya closed basin, especially in recent years, faced several negative effects. Lack of rainfall and water sources, climate change and drought, development of industry, and untreated domestic and industrial wastewater discharges, nonefficient water consumption for agricultural purposes, drainage water from agriculture, drop in groundwater level, solid waste disposal problem are main sources of these effects.

In this work, 9 monitoring stations were selected for investigation of OCPs and heavy metal pollution within the basin. All sampling locations are marked on the site map of the study area (Figure 1).

2.3. Analytical Methods. The sampling, preservation, transportation, and analysis of the water samples were performed 
following standard methods. All samples were collected free of air bubbles in $1 \mathrm{~L}$, glass containers and they were stored in the dark at $4^{\circ} \mathrm{C}$. Water samples collected from sampling points were analyzed for heavy metals (As, $\mathrm{Cu}, \mathrm{Cr}, \mathrm{Fe}$, $\mathrm{Mn}$, and $\mathrm{Ni}$ ) and OCPs. Concentrations of heavy metals in water samples were determined by using Inductively Coupled Plasma/Mass Spectrometry (ICP/MS, Perkin Elmer) following standard guidelines and procedures [13]. Analytical curves were drawn using eight points. The calibration curves gave a high level of linearity for all studied heavy metals with correlation coefficients ranging between 0.9983 and 0.9999 . The LOD values were found to be in the low ppb level, ranging from 0.0047 to $0.2210 \mu \mathrm{g} / \mathrm{L}$.

In order to determine trace levels of OCPs, an extraction and preconcentration step is necessary. LLE procedure was adopted from US EPA Method 3510C [14]. Water sample $(200 \mathrm{~mL})$ was placed in a $250 \mathrm{~mL}$ separatory funnel. The extraction was carried out three times with $20 \mathrm{~mL}$ of dichloromethane. The extracts were combined and dried with anhydrous sodium sulfate. The resulting extract was concentrated to $1 \mathrm{~mL}$ using rotary evaporator (Buchi B-160 Vocabox, Flawil 1, Switzerland) and gentle nitrogen stream and transferred into the vial. Then, gas chromatography mass spectrometer (GC/MS) analysis was performed as described in Section 2.4. The limits of detection (LODs), based on a signal-to-noise ratio $(\mathrm{S} / \mathrm{N})$ of 3 [15] for OCPs, were in the range of $0.005-0.052 \mu \mathrm{g} / \mathrm{L}$ for OCPs. The calibration techniques for OCPs are the external standard multipoint calibration using at least five concentration levels. For spiking concentration of OCPs at levels of $0.1 \mu \mathrm{g} / \mathrm{L}, 1 \mu \mathrm{g} / \mathrm{L}$, and $5 \mu \mathrm{g} / \mathrm{L}$, the recovery rates after extraction and concentration procedures were in the range of $85-102 \%$ with relative standard deviation $<5 \%$.

2.4. Gas Chromatography/Mass Spectrometry (GC/MS) Conditions. The determination of OCPs was carried out by gas chromatograph (GC, Agilent 6890N, Agilent Technologies, Palo Alto, CA, USA) equipped with mass-selective detector (MS, Agilent 5973, Agilent Technologies, Foster City, CA, USA). The features and operating conditions of GC/MS system were as follows: GC, equipped with programmed temperature vaporizing (PTV) injector, DB-5 MS 5\% phenylmethylsiloxane fused silica capillary column $(30 \mathrm{~m}$ length, $0.25 \mathrm{~m}$ i.d. and $0.25 \mu \mathrm{m}$ film thickness), and helium (purity 99.999\%) as carrier gas at constant flow-rate of $1.9 \mathrm{~mL} / \mathrm{min}$. The injection volume was $2 \mu \mathrm{L}$ and PTV was operated in splitless mode. Injections were performed by an Agilent 7683 B Series automatic injector (Agilent Technologies, Palo Alto, CA, USA). PTV program was as follows: $80^{\circ} \mathrm{C}, 12^{\circ} \mathrm{C} / \mathrm{s}$ to $350^{\circ} \mathrm{C}$ and hold at $350{ }^{\circ} \mathrm{C}$ for $2 \mathrm{~min}$. The temperature of the ion source and $\mathrm{MS}$ transfer line were maintained at $170^{\circ} \mathrm{C}$ and $280^{\circ} \mathrm{C}$, respectively. The oven program for OCPs was the same as reported by Ozcan [16]. MS detector was operated in selected ion monitoring (SIM) mode.

\section{Results and Discussion}

3.1. Levels of OCP Residues in Water Samples. The concentration ranges of OCPs residues and total concentrations
TABLE 1: The levels of OCPs residues in surface water samples in March 2012 and August $2012(\mu \mathrm{g} / \mathrm{L})$.

\begin{tabular}{lcc}
\hline OCPs & $\begin{array}{c}\text { March 2012 } \\
\text { Minimum-maximum }\end{array}$ & $\begin{array}{c}\text { August 2012 } \\
\text { Minimum-maximum }\end{array}$ \\
\hline$\alpha$-HCH & $0.005-0.010$ & nd-0.005 \\
$\beta$-HCH & $0.005-0.020$ & nd-0.005 \\
$\gamma$-HCH & $0.005-0.010$ & nd-0.005 \\
$\delta$-HCH & nd-0.015 & nd-0.010 \\
$\sum$ HCHs & $\mathbf{0 . 0 1 5 - 0 . 0 6 5}$ & nd-0.025 \\
p,p'-DDE & nd-0.037 & nd-0.010 \\
p,p'-DDD & nd-0.005 & nd \\
p,p'-DDT & nd-0.005 & nd \\
$\sum$ DDTs & nd-0.047 & nd-0.010 \\
Heptachlor & nd-0.005 & nd \\
Heptachlor epoxide & nd-0.025 & $0.005-0.015$ \\
Aldrin & $0.055-0.220$ & $0.005-0.040$ \\
Chlordane-I & nd-0.005 & nd \\
Chlordane-II & nd & nd-0.010 \\
Endosulfan-I & $0.005-0.025$ & nd-0.005 \\
Endosulfan-II & $0.095-0.165$ & $0.005-0.080$ \\
Endosulfan sulfate & nd-0.015 & nd \\
Dieldrin & nd-0.015 & nd-0.010 \\
Endrin & $0.005-0.015$ & $0.005-0.010$ \\
Endrin aldehyde & $0.015-0.035$ & nd-0.005 \\
Endrin ketone & nd-0.010 & nd-0.010 \\
Methoxychlor & nd & nd \\
\hline
\end{tabular}

nd: not detected.

of HCHs ( $\sum \mathrm{HCHs}$ ) and DDTs ( $\mathrm{HDDTs}$ ) in surface water samples are presented in Table 1 . All $\mathrm{HCH}$ isomers were determined in water samples from Konya closed basin. For March 2012 and August 2012, the concentrations of $\sum \mathrm{HCH}$ were in the range $(0.015-0.065) \mu \mathrm{g} / \mathrm{L}$ and (not detected$0.025) \mu \mathrm{g} / \mathrm{L}$, respectively. In addition, the levels of each $\mathrm{HCH}$ isomer determined in the samples taken from March 2012 were higher than those taken from August 2012. For sampling period March 2012, of all $\mathrm{HCH}$ isomers investigated, $\beta-\mathrm{HCH}$ was the dominant substance determined with a range of 0.005-0.020 $\mu \mathrm{g} / \mathrm{L}$. Qu et al. [17] reported that the commercial $\mathrm{HCH}$ consists of a mixture of $\mathrm{HCH}$ isomers including 65$70 \%$ of $\alpha-\mathrm{HCH}, 7-10 \%$ of $\beta-\mathrm{HCH}, 14-15 \% \gamma-\mathrm{HCH}$, and $10 \%$ of $\delta$ - $\mathrm{HCH}$ and other constituents. Because $\alpha-\mathrm{HCH}$ is instable in the environment, it is easy to metabolized into $\beta-\mathrm{HCH}$ [17]. Thus, $\beta-\mathrm{HCH}$ is the main isomer determined in most water samples.

Comparison of $\mathrm{HCH}$ levels in the water samples of this study with surface water samples from different region in Turkey, the range of $\sum \mathrm{HCHs}(0.015-0.065$ and not detected$0.025 \mu \mathrm{g} / \mathrm{L}$ for each sampling period) was less than those found water sample from Küçük Menderes River (0.101$0.559 \mu \mathrm{g} / \mathrm{L}$ ) [18]. In another study of Turgut and Fomin [19], the concentration of $\delta$ - $\mathrm{HCH}$ was $2.065 \mu \mathrm{g} / \mathrm{L}$, which is more than levels of $\delta$-HCH determined in our study.

In the case of DDT isomers, DDE, DDD, and DDT were determined in all water samples. Among these isomers, DDE 
TABLE 2: The levels of heavy metals in surface water samples in March 2012 and August $2012(\mu \mathrm{g} / \mathrm{L})$.

\begin{tabular}{lcc}
\hline Heavy metals & $\begin{array}{c}\text { March 2012 } \\
\text { Minimum- } \\
\text { maximum } \\
\text { (median) }\end{array}$ & $\begin{array}{c}\text { August 2012 } \\
\text { Minimum- } \\
\text { maximum } \\
\text { (median) }\end{array}$ \\
\hline $\mathrm{As}$ & nd-14.77 (3.11) & $1.32-91.11(4.73)$ \\
$\mathrm{Cu}$ & $\mathrm{nd}-7.89(1.85)$ & $0.60-5.63(1.10)$ \\
$\mathrm{Cr}$ & $\mathrm{nd}-5.49(3.14)$ & $13.37-40.94(19.73)$ \\
$\mathrm{Ni}$ & $\mathrm{nd}-15.46(2.48)$ & $1.24-6.38(2.30)$ \\
$\mathrm{Fe}$ & $\mathrm{nd}-1273(266)$ & $148.89-296.60$ \\
$\mathrm{Mn}$ & $\mathrm{nd}-39.22(1.19)$ & $(165.53)$ \\
\hline
\end{tabular}

nd: not detected.

was detected with the highest concentration range between not detected to $0.037 \mu \mathrm{g} / \mathrm{L}$. This result is most probably the result of banning the use of DDT in Turkey. The range of $\sum$ DDTs' levels in this study was considerably lower in comparison to another river and water reservoir in Turkey [19-21] and in Bay of Ohuira, Mexico [22].

The level of heptachlor in the samples taken from March 2012 was in the range from not detected to $0.005 \mu \mathrm{g} / \mathrm{L}$ and it was not determined in the samples from August 2012. The concentration of heptachlor in this study was more than the sample $(5.9 \mathrm{pg} / \mathrm{L})$ of Lake Baikal, Siberia, which is reported by Kuckllck et al. [23].

The concentration range of aldrin in all samples taken from March (0.055-0.220 $\mu \mathrm{g} / \mathrm{L})$ and August 2012 (0.005$0.040 \mu \mathrm{g} / \mathrm{L}$ ) was more than those from dieldrin (not detected$0.015 \mu \mathrm{g} / \mathrm{L}$ and not detected- $0.010 \mu \mathrm{g} / \mathrm{L}$ for March and August 2012, resp.). According to Blus et al. [24], aldrin is rapidly broken down to dieldrin. Based on this result, it can be concluded that fresh input of aldrin in the Konya closed basin still occurs.

Among the endosulfans, the highest concentration range belongs to endosulfan-II $(0.095-0.165 \mu \mathrm{g} / \mathrm{L}$ and $0.005-$ $0.080 \mu \mathrm{g} / \mathrm{L}$ for March and August 2012, resp.). This result was against the results which is reported by Osuna-Flores and Riva [22] that the endosulfan-I had the highest concentration $(0.010-1.260 \mu \mathrm{g} / \mathrm{L})$ in surface water samples from Bay of Ohuria, Mexico. Turgut [18] also reported that endosulfan sulfate had the highest concentration with the range of 0.028 $0.123 \mu \mathrm{g} / \mathrm{L}$ in the samples of Küçük Menderes River in Turkey.

The endrin concentration in this study ranged from 0.005 to $0.015 \mu \mathrm{g} / \mathrm{L}$. Other endrin metabolites (endrin aldehyde and endrin ketone) were also determined in samples of March and August 2012 (Table 1). The level of endrin was comparable with that reported for the water samples of Küçük Menderes River [18] and it was less than those in the river and water reservoir in Göksu Delta with a maximum median concentration of $21 \mu \mathrm{g} / \mathrm{L}$ [20].

3.2. Levels of Heavy Metals in Water Samples. The results on the levels of heavy metals in surface waters in Konya closed basin are shown in Table 2. In March 2012 among the heavy
TABLE 3: Limit values for heavy metals for drinking water quality and protection of freshwater aquatic life, $\mu \mathrm{g} / \mathrm{L}$.

\begin{tabular}{lcccc}
\hline Heavy metals & TRWHC & WHO & USEPA & EU \\
\hline As & 10 & 10 & 10 & 10 \\
$\mathrm{Cr}$ & 50 & 50 & 10 & 50 \\
$\mathrm{Cu}$ & 50 & 50 & 10 & 50 \\
$\mathrm{Fe}$ & 200 & 300 & 300 & 200 \\
$\mathrm{Mn}$ & 50 & 500 & 50 & 50 \\
$\mathrm{Ni}$ & 20 & - & - & 20 \\
$\mathrm{Zn}$ & - & - & 5000 & - \\
\hline
\end{tabular}

metals, Cr had the least concentration range (not detected5.49, median: $3.14 \mu \mathrm{g} / \mathrm{L}$ ). While, the results for samples of August 2012 showed that $\mathrm{Cu}$ had the least concentration range $(0.60-5.63$, median: $1.10 \mu \mathrm{g} / \mathrm{L})$. It is seen in Table 2 that the order of the median level of heavy metals in water samples from March and August 2012 was $\mathrm{Mn}<\mathrm{Cu}<\mathrm{Ni}<\mathrm{As}<$ $\mathrm{Cr}<\mathrm{Fe}$.

The limit values of heavy metals for drinking water quality recommended by EU [31], US EPA [32], WHO [33] and Turkish Regulation [34] and for the protection of freshwater aquatic life [35] are presented in Table 3. A comparison for the maximum concentrations of $\mathrm{As}, \mathrm{Cr}, \mathrm{Cu}, \mathrm{Fe}, \mathrm{Mn}$ and $\mathrm{Ni}$ in surface waters of the Konya closed basin with those in other rivers is also presented in Table 4.

The concentrations of As in some water samples (27\% of all samples) exceeded the maximum permitted concentration for drinking water quality guidelines. This poses a threat to human health because of high carcinogenic effect of As [36]. Similarly, Fe concentration of $22 \%$ of all samples were higher than the guideline values. The concentration of $\mathrm{Cr}$ was lower than the limits values, except for US EPA limit. $\mathrm{Cu}, \mathrm{Ni}$, and Mn had concentrations that are below the guideline values. High level of Fe may be a source of high As concentration in the samples. Reduction of iron oxyhydroxide $(\mathrm{FeOOH})$ and release of its sorbed As load to solution which is the most common mechanism that pollutes water [37].

\section{Conclusion}

The results from this study provide important data for the literature because it is the first study that report the levels of OCPs and heavy metals of surface water in Konya closed basin (Turkey). The results showed the most of studied OCPs were determined in water samples. In general, the concentrations of OCPs were mostly comparable or less than data in the literature. Among the heavy metals, As and Fe were of concentrations that are higher than EU, WHO, US EPA, and Turkish regulation limits for drinking water. However, $\mathrm{Cu}, \mathrm{Ni}$, and $\mathrm{Mn}$ had lower concentrations than regulation limits. Arsenic is a threat to human health with its high carcinogenic effect. Chronic effects on humans may be caused by prolonged consumption of water with even very low concentrations. The high level of Fe was observed in water sources, which is a possible source of As enrichment in the study area. It is concluded that a risk determination about 
TABle 4: The maximum concentration of $\mathrm{As}, \mathrm{Cr}, \mathrm{Cu}, \mathrm{Fe}, \mathrm{Mn}$, and $\mathrm{Ni}$ in water samples from other rivers in the literature.

\begin{tabular}{|c|c|c|c|c|c|c|c|}
\hline \multirow{2}{*}{ Location } & \multicolumn{7}{|c|}{ Maximum concentration, $\mu \mathrm{g} / \mathrm{L}$} \\
\hline & As & $\mathrm{Cr}$ & $\mathrm{Cu}$ & $\mathrm{Fe}$ & $\mathrm{Mn}$ & $\mathrm{Ni}$ & Reference \\
\hline Khoshk River, Iran & - & 550 & 60 & - & 540 & 200 & {$[25]$} \\
\hline San Petro River, Mexico & 160 & 212 & 200 & 1800 & 4620 & 300 & {$[26]$} \\
\hline Sakarya River, Turkey & - & 228 & 4362 & - & - & 4977 & [27] \\
\hline Axios River, Greece & 10.9 & 4.2 & 13.7 & - & - & 8.2 & {$[28]$} \\
\hline Odra River, Poland & 8.1 & 12.7 & 54.6 & 1861 & 353 & 27.2 & [29] \\
\hline Vardar River, Macedonia & - & - & 98 & 1904 & 249 & - & {$[30]$} \\
\hline Samples in Konya closed basin & 91.11 & 40.94 & 7.89 & 1273 & 39.22 & 15.46 & This study \\
\hline
\end{tabular}

the occurrence and source of As and $\mathrm{Fe}$ is needed for the whole basin and realistic risk reduction measures must be developed.

\section{References}

[1] D. Cicchella, B. de Vivo, A. Lima, S. Albanese, R. A. R. McGill, and R. R. Parrish, "Heavy metal pollution and $\mathrm{Pb}$ isotopes in urban soils of Napoli, Italy," Geochemistry, vol. 8, no. 1, pp. 103$112,2008$.

[2] S. Wu, S. Zhou, and X. Li, "Determining the anthropogenic contribution of heavy metal accumulations around a typical industrial town: Xushe, China," Journal of Geochemical Exploration, vol. 110, no. 2, pp. 92-97, 2011.

[3] G. Zarazua, P. Ávila-Pérez, S. Tejeda, I. Barcelo-Quintal, and T. Martínez, "Analysis of total and dissolved heavy metals in surface water of a Mexican polluted river by total reflection Xray fluorescence spectrometry," Spectrochimica Acta B, vol. 61, no. 10-11, pp. 1180-1184, 2006.

[4] W. Luo, Y. Lu, T. Wang et al., "Ecological risk assessment of arsenic and metals in sediments of coastal areas of northern Bohai and Yellow Seas, China," AMBIO: A Journal of the Human Environment, vol. 39, pp. 367-375, 2010.

[5] P. Guo, Y. Gong, C. Wang, X. Liu, and J. Liu, "Arsenic speciation and effect of arsenate inhibition in a Microcystis aeruginosa culture medium under different phosphate regimes," Environmental Toxicology and Chemistry, vol. 30, no. 8, pp. 1754-1759, 2011.

[6] B. Debelius, J. M. Forja, and L. M. Lubián, “Toxicity of copper, nickel and zinc to Synechococcus populations from the Strait of Gibraltar," Journal of Marine Systems, vol. 88, no. 1, pp. 113-119, 2011.

[7] H. Iwata, S. Tanabe, N. Sakai, A. Nishimura, and R. Tatsukawa, "Geographical distribution of persistent organochlorines in air, water and sediments from Asia and Oceania, and their implications for global redistribution from lower latitudes," Environmental Pollution, vol. 85, no. 1, pp. 15-33, 1994.

[8] K. L. Foster, M. L. Mallory, L. Hill, and J. M. Blais, "PCB and organochlorine pesticides in northern fulmars (fulmarusglacialis) from a high arctic colony: chemical exposure, fate, and transfer to predators," Environmental Toxicology and Chemistry, vol. 30, pp. 2055-2064, 2011.

[9] W. Chen, M. Jing, J. Bu et al., "Organochlorine pesticides in the surface water and sediments from the Peacock River Drainage Basin in Xinjiang, China: a study of an arid zone in Central Asia," Environmental Monitoring and Assessment, vol. 177, no. 1-4, pp. 1-21, 2011.
[10] H. S. Wang, Y. G. Zhao, Y. B. Man, C. K. C. Wong, and M. $\mathrm{H}$. Wong, "Oral bioaccessibility and human risk assessment of organochlorine pesticides (OCPs) via fish consumption, using an in vitro gastrointestinal model," Food Chemistry, vol. 127, no. 4, pp. 1673-1679, 2011.

[11] S. Ş. Köprücü, K. Köprücü, M. Ş. Ural, U. Ispir, and M. Pala, "Acute toxicity of organophosphorous pesticide diazinon and its effects on behavior and some hematological parameters of fingerling European catfish (Silurus glanis L.)," Pesticide Biochemistry and Physiology, vol. 86, no. 2, pp. 99-105, 2006.

[12] WWF-Turkey, Project Final Report of Turkey's Last, World Wildlife Fund, 2010.

[13] APHA, AWWA, and WEF, Standard Methods For the Examination of Water and waste Water, American Public Health Association, Washington, DC, USA, 20th edition, 1998.

[14] US EPA, "Method 3510C, Separatory Funnel Liquid-Liquid Extraction," SW846 CH 4.2.1, 1996.

[15] A. Tor and M. E. Aydin, "Application of liquid-phase microextraction to the analysis of trihalomethanes in water," Analytica Chimica Acta, vol. 575, no. 1, pp. 138-143, 2006.

[16] S. Ozcan, "Viable and rapid determination of organochlorine pesticides in water," Clean-Soil, Air, Water, vol. 38, no. 5-6, pp. 457-465, 2010.

[17] W. Qu, R. P. S. Suri, X. Bi, G. Sheng, and J. Fu, "Exposure of young mothers and newborns to organochlorine pesticides (OCPs) in Guangzhou, China," Science of the Total Environment, vol. 408, no. 16, pp. 3133-3138, 2010.

[18] C. Turgut, “The contamination with organochlorine pesticides and heavy metals in surface water in Küçük Menderes River in Turkey, 2000-2002," Environment International, vol. 29, no. 1, pp. 29-32, 2003.

[19] C. Turgut and A. Fomin, "Residues of selected pesticides in the Küçük Menderes river in Turkey," Zeitschrift für PflKrankh und Pflschutz, vol. 18, pp. 1053-1057, 2002.

[20] Z. Ayas, N. Barlas, and D. Kolankaya, "Determination of organochlorine pesticide residues in various environments and organisms in Goksu Delta, Turkey," Aquatic Toxicology, vol. 39, no. 2, pp. 171-181, 1997.

[21] N. E. Barlas, "Determination of organochlorine pesticide residues in aquatic systems and organisms in upper Sakarya Basin, Türkiye," Bulletin of Environmental Contamination and Toxicology, vol. 62, pp. 278-285.

[22] I. Osuna-Flores and M. C. Riva, "Organochlorine pesticide residue concentrations in shrimps, sediments, and surface water from bay of Ohuira, Topolobampo, Sinaloa, Mexico," Bulletin of Environmental Contamination and Toxicology, vol. 68, no. 4, pp. 532-539, 2002. 
[23] J. R. Kuckllck, T. F. Bldleman, L. L. McConnell, M. D. Walla, and G. P. Ivanov, "Organochlorines in the water and biota of Lake Baikal, Siberia," Environmental Science and Technology, vol. 28, no. 1, pp. 31-37, 1994.

[24] L. J. Blus, C. J. Henny, T. E. Kaiser, and R. A. Grove, "Effects of wildlife from use of endrin in Washington state orchards," Transactions of the North American Wildlife and Natural Resources Conference, vol. 48, pp. 159-174, 1983.

[25] S. Salati and F. Moore, "Assessment of heavy metal concentration in the Khoshk River water and sediment, Shiraz, Southwest Iran," Environmental Monitoring and Assessment, vol. 164, no. 14, pp. 677-689, 2010.

[26] R. L. Gutiérrez, H. Rubio-Arias, R. Quintana, J. A. Ortega, and M. Gutierrez, "Heavy metals in water of the San Pedro River in Chihuahua, Mexico and its potential health risk," International Journal of Environmental Research and Public Health, vol. 5, no. 2, pp. 91-98, 2008.

[27] M. S. Dundar and H. Altundag, "Investigation of heavy metal contaminations in the lower Sakarya river water and sediments," Environmental Monitoring and Assessment, vol. 128, no. 1-3, pp. 177-181, 2007.

[28] A. P. Karageorgis, N. P. Nikolaidis, H. Karamanos, and N. Skoulikidis, "Water and sediment quality assessment of the Axios River and its coastal environment," Continental Shelf Research, vol. 23, no. 17-19, pp. 1929-1944, 2003.

[29] E. Adamiec and E. Helios-Rybicka, "Distribution of pollutants in the odra river system part IV. Heavy metal distribution in water of the upper and middle Odra river, 1998-2000," Polish Journal of Environmental Studies, vol. 11, no. 6, pp. 669-673, 2002.

[30] Z. Levkov and S. Krstic, "Use of algae for monitoring of heavy metals in the River Vardar, Macedonia," Mediterranean Marine Science, vol. 3, pp. 99-112, 2002.

[31] EC, "The quality of water intended to human consumption. Directive 1998/83/EC," Official Journal L330/05.12.1998, European Community, 1998.

[32] USEPA, National Recommended Water Quality Criteria, United States Environmental Protection Agency. Office of Water, Office of Science and Technology, 2006.

[33] WHO, Guidelines for Drinking Water Quality, World Health Organization, Geneva, Switzerland, 3rd edition, 2004.

[34] TRWHC, Regulations of Waters for Human Consumption, 25730, Ministry of Environment and Forestry, Turkish Official Gazette, 2005.

[35] USEPA, "National primary drinking water regulations," EPA 816-F-09-004, United States Environmental Protection Agency, 2009.

[36] IARC, Arsenic and Arseniccompounds (Group 1), IARC Monographs on the Evaluation of the Carcinogenic Risks to Humans, 1987.

[37] P. Ravenscroft, J. M. McArthur, and B. A. Hoque, "Geochemical and palaeohydrological controls on pollution of groundwater by arsenic," in Arsenic Exposure and Health Effects IV, W. R. Chappell, C. O. Abernathy, and R. L. Calderon, Eds., pp. 53-77, Elsevier, Oxford, UK, 2001. 

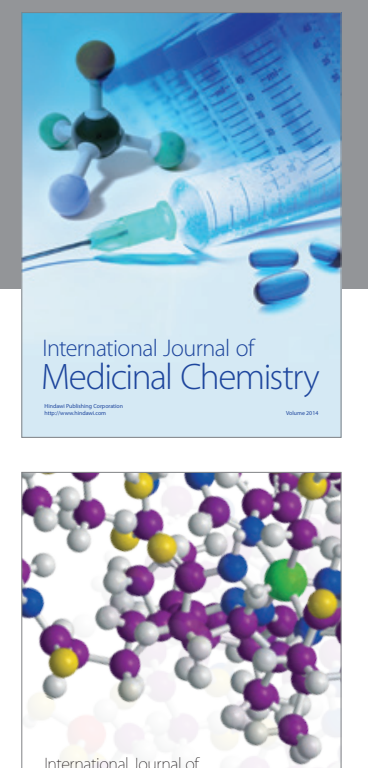

\section{Carbohydrate} Chemistry

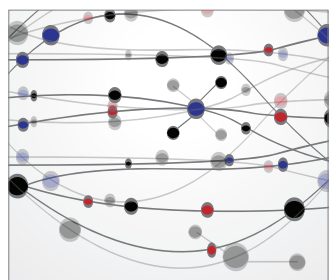

The Scientific World Journal
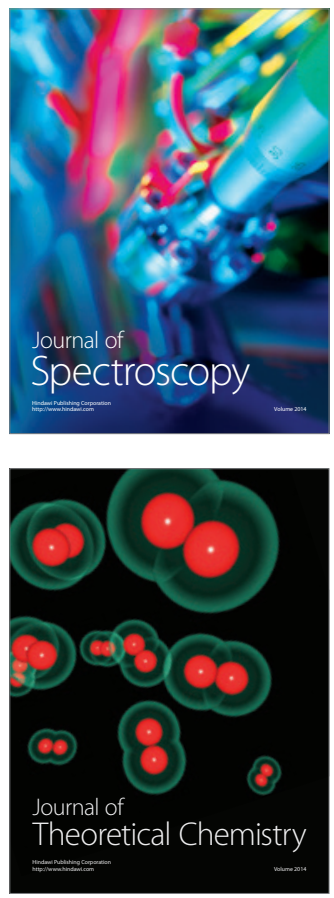
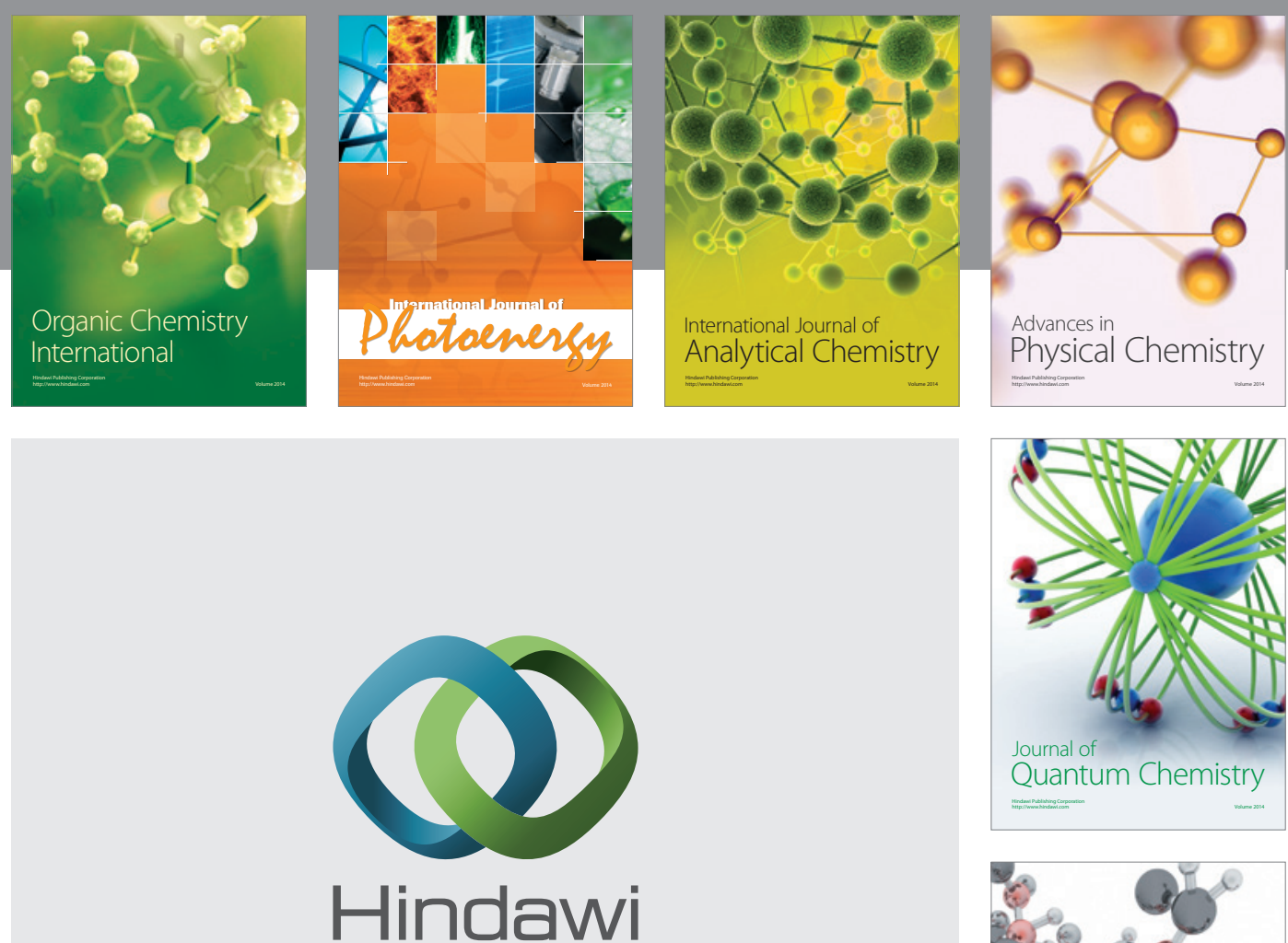

Submit your manuscripts at

http://www.hindawi.com

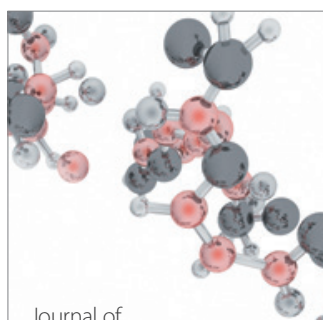

Analytical Methods

in Chemistry

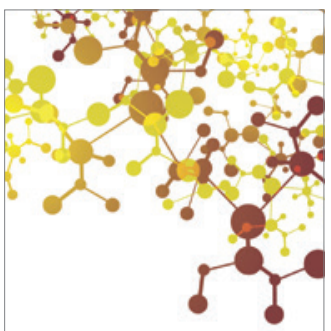

Journal of

Applied Chemistry

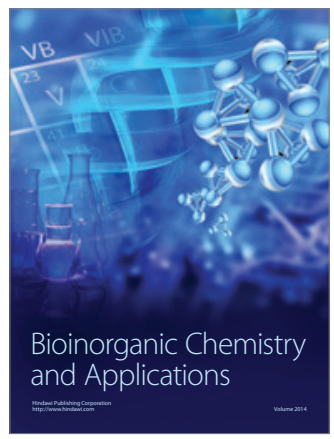

Inorganic Chemistry
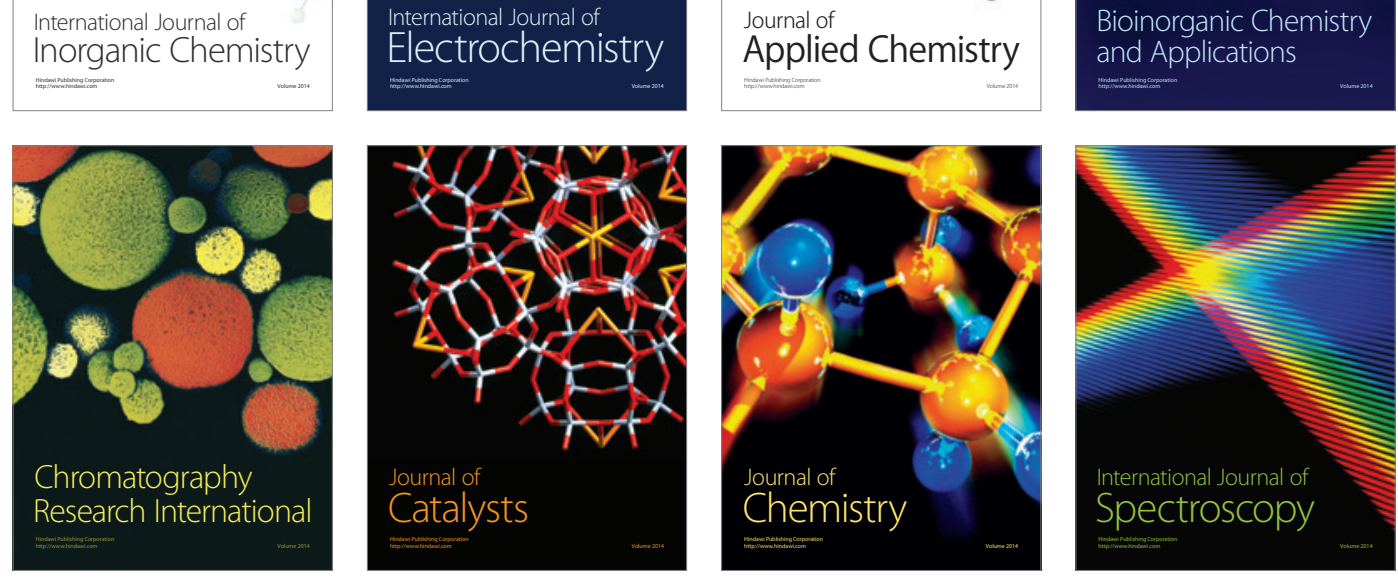